\title{
Mesoscale grid rainfall estimation from AVHRR and GMS data.
}

\begin{abstract}
Areal rainfall averages derived from rain-gauge observations suffer from limitations not only due to sampling but also because gauges are usually distributed with a spatial bias towards populated areas and against areas with high elevation and slope. For a large river basin, however, heavy rainfall in the mountain upstream can result in severe flooding downstream. In this study, cloud-indexing and cloud model-based techniques were applied to Advanced Very High Resolution Radiometer (AVHRR) and Geostationary Meteorological Satellite (GMS) imager data based on the cloud-top brightness temperature (T B) and processed for estimating mesoscale grid rainfall. This study aims to improve and refine rainfall estimation in Malaysian monsoons based on cloud model techniques for operational pre-flood forecasting using readily available near-real-time satellite data such as the National Oceanic and Atmospheric Administration (NOAA)-AVHRR and GMS imager. Rain rates between 3 and $12 \mathrm{~mm} \mathrm{~h}-1$ were assigned to cloud pixels of hourly coverage AVHRR or GMS data over the Langat Basin area for the duration of the monsoon rainfall event of 27 September to 8 October 2000 in Malaysia. The observed rainfall and quantitative precipitation forecast (QPF) showed an R 2 value of 0.9028 , while the observed rainfall run-off (RR; recorded) and its simulated data had an R 2 value of 0.9263 and the QPF run-off and its simulated data had an $\mathrm{R} 2$ value of 0.815 . The rainfall estimate was used to simulate the flood event of the catchment. The estimated rainfall over the catchment showed similar flood area coverage to the observed flood event.
\end{abstract}

Keyword: Remote sensing; Rainfall estimation; Flood 